\title{
Factors That Influence the Measurement of Prostate Cancer DNA Ploidy and Proliferation in Paraffin Embedded Tissue Evaluated by Flow Cytometry
}

\author{
Mathew J. So, John C. Cheville, M.D., Jerry A. Katzmann, Ph.D., Darren L. Riehle, B.S., \\ Christine M. Lohse, B.S., V. Shane Pankratz, Ph.D., Thomas J. Sebo, M.D., Ph.D. \\ Swarthmore College, Swarthmore, Pennsylvania (MJS); and Department of Laboratory Medicine and \\ Pathology (JCC, JAK, DLR, TJS), and Section of Biostatistics (CML, VSP), Mayo Clinic, Rochester, \\ Minnesota
}

DNA ploidy and proliferation have been shown in several studies to be prognostic markers for prostate cancer. Flow cytometry (FCM) is often used in the determination of ploidy and proliferation. However, FCM cannot readily distinguish among benign epithelium, stromal and inflammatory cells, high grade prostatic intraepithelial neoplasia (HGPIN), and cancer cells. In this study, we evaluated H\&E histologic features of 322 radical prostatectomy formalin-fixed, paraffin-embedded tissue blocks used for determining DNA ploidy, percent S-phase (\%S), and \%S + \%G2M by FCM. The microscopic findings included Gleason score, extent of cancer and HGPIN in the tissue block, and presence of a needle track. The amount of cancer in the block was expressed as a percentage of the total tissue surface area in quartiles: $\leq \mathbf{2 5 \%}, \mathbf{2 6}-\mathbf{5 0 \%}, \mathbf{5 1}-\mathbf{7 5 \%}$, and $\geq 76 \%$. The extent of HGPIN was recorded in rough $5 \%$ intervals. Needle track effect was defined as a combination of fibrohistiocytic reaction, fibrin clot, granuloma formation, and chronic inflammation. The associations between these histologic features and DNA ploidy and proliferation $(\% \mathrm{~S}$ and $\% \mathrm{~S}+$ \%G2M) were assessed. In multivariate analyses, Gleason score, the amount of tumor in the tissue block, and the extent of HGPIN were significantly associated with ploidy. Gleason score was the only parameter significantly associated with the proliferation measure of \%S. If we included \%G2M as part of the proliferative fraction of the histogram, however, both Gleason score and the amount of tumor in the block were significantly associated with this

Copyright (C) 2001 by The United States and Canadian Academy of Pathology, Inc.

VOL. 14, NO. 9, P. 906, 2001 Printed in the U.S.A.

Date of acceptance: May 25, 2001.

Address reprint requests to: Thomas J. Sebo, M.D., Ph.D., Mayo Clinic, Department of Laboratory Medicine and Pathology, Hilton 11, 200 First Street SW, Rochester, MN 55905; e-mail: sebo.thomas@mayo.edu; fax: 507-284-1599. measure of proliferation. The presence of a needle track was not significantly associated with DNA ploidy, \%S, or \%S + \%G2M. In summary, prostate cancer DNA ploidy and proliferation results assessed by FCM in paraffin-embedded tissue blocks were associated with the Gleason score, amount of cancer in the tissue block, and extent of HGPIN. However, the presence of a needle track was not associated with the FCM results.

KEY WORDS: DNA ploidy, Flow cytometry, Tumor volume, Needle track, Prostate, Carcinoma, High grade prostatic intraepithelial neoplasia, Prostatectomy.

Mod Pathol 2001;14(9):906-912

DNA ploidy (1-6) and proliferation $(7,8)$ have been shown to provide prognostic information for prostate cancer. Studies examining the relationship between ploidy and proliferation and patient outcome are often based upon flow cytometry (FCM) data using formalin-fixed, paraffin-embedded tissue from radical retropubic prostatectomy (RRP) specimens. However, FCM cannot readily distinguish among benign epithelial, stromal, and inflammatory cells, high grade prostatic intraepithelial neoplasia (HGPIN), and cancer cells. Furthermore, studies that do not show DNA ploidy and proliferation as independent prognostic markers emphasize the strong correlation of cancer Gleason score with DNA ploidy and proliferation (9-11).

To the best of our knowledge, there are no published reports directly assessing the degree to which non-invasive tumor components in paraffinembedded tissue blocks are associated with prostate cancer ploidy and proliferation results determined by FCM. In this study, we evaluated hematoxylin and eosin (H\&E) histologic features from 322 RRP formalin-fixed, paraffin-embedded tissue specimens used for determining DNA ploidy, 
percent S-phase $(\% \mathrm{~S})$, and $\% \mathrm{~S}+\% \mathrm{G} 2 \mathrm{M}$ by FCM. The histologic features included Gleason score of the prostate cancer, amount of cancer in the tissue block, presence of a needle track, and the extent of HGPIN. These features were then compared to DNA ploidy and proliferation (\%S and $\% \mathrm{~S}+\% \mathrm{G} 2 \mathrm{M})$ as determined by FCM. The 322 cases represented a consecutive series of Mayo Clinic registered patients undergoing outpatient needle biopsy and subsequent RRP between 1995 and 1998.

\section{MATERIALS AND METHODS}

\section{Clinical Features and Radical Retropubic Prostatectomy (RRP) Specimens}

Four hundred fifty-four consecutive patients undergoing outpatient needle biopsies were diagnosed with cancer between January 1995 and December 1998. All patients were treated with RRP without preoperative adjuvant hormonal therapy. At Mayo Clinic, our urologists routinely request DNA ploidy as a prognostic marker. The pathologist then determines which tissue block to process for ploidy evaluation. Two methods are employed: flow cytometry (FCM) and digital image analysis (DIA). DIA is performed when the percent of tumor in the tissue specimen represents less than $10 \%$ of the overall surface area. Otherwise, FCM is utilized. With this processing mechanism, 322 of the 454 RRP specimens had ploidy determined by FCM and slides available for review.

The prostate glands were evaluated at the time of surgery by a standardized, limited sampling protocol employing frozen section technique, followed by re-evaluation the following day with H\&E permanent sections. The prostate specimen, in a fresh state, was initially assessed by microscopically examining 5 surgical margins (right and left apex, right and left bladder base, and distal urethra). This was followed by 8 standard sections through the peripheral zone of the right and left lobes and right and left seminal vesicles. The average (SD) number of tissue sections evaluated per RRP specimen was 13.7 (1.9), ranging from 13 to 29. Overall tumor volume in the RRP specimen was calculated using the three dimensional measurements of the tumor made at the time of initial evaluation. Extraprostatic extension (EPE) was defined as seminal vesicle involvement, malignant cells outside the prostatic capsule (in adipose or ganglion tissue), or lymph node metastases. The formalin-fixed, paraffinembedded tissue block that contained the most cancer and highest Gleason score was processed for flow cytometric assessment of DNA ploidy and proliferation (\%S and \%S + \%G2M).

Microscopic features of the tissue block used for FCM were retrospectively reviewed with consensus by the two study pathologists (TJS and JCC) using H\&E slides. Gleason score of the tumor and the predominant Gleason pattern were recorded. The amount of cancer in the block was evaluated relative to the amount of benign tissue and expressed as a percent, in quartiles, of the total surface area: $\leq 25 \%, 26 \%-50 \%, 51 \%-75 \%$, and $\geq 76 \%$. Histologic evidence of a needle track was defined as a combination of fibrohistiocytic cell reaction, fibrin clot, granuloma formation, and dense chronic inflammation. The extent of HGPIN present was recorded as the percent surface area in rough $5 \%$ intervals.

\section{Flow Cytometry}

Flow cytometry was performed as previously described (12). The nuclear content of 10,000 nuclei was measured with a FACScan (Becton Dickinson, Sunnyvale, CA.) flow cytometer. Cell cycle evaluation of the DNA histograms was performed with a Modfit 5.2 (Verity Software, Topsham, ME) computerized software program. Tumors with only one identifiable gap0 -gapl peak were classified as diploid (2n). Tumor samples that contained a significant increase in the $4 \mathrm{n}$ peak (more than $9 \%$ of nuclei) and an identifiable $8 \mathrm{n}$ population were categorized as tetraploid. Tumor DNA content was classified as DNA aneuploid if a separate, identifiable gap0 -gap1 peak was present. Tumor samples that did not fit into one of these categories were considered unclassifiable. The DNA index was calculated as the ratio of the mean channel number of the aneuploid gap0 -gap1 peak to the mean channel number of the diploid $2 \mathrm{n}$ peak. DNA diploid tumors therefore had a DNA index of 1.00. All tissue blocks and DNA histograms were analyzed and classified without knowledge of a patient's clinicopathologic features.

\section{Statistical Analysis}

Univariate and multivariate statistical models were used to determine the relationships between the histologic features and both DNA ploidy and proliferation. Prediction models for DNA ploidy and proliferation were developed using multivariate logistic and linear regression, respectively. Logistic models with an ordered response (diploid, tetraploid, and aneuploid) require the assumption that the odds of a tetraploid tumor compared to a diploid tumor are the same as the odds of an aneuploid tumor compared to a tetraploid tumor. An initial analysis indicated that this assumption was not appropriate for these data; thus, two prediction models for DNA ploidy were developed. The first model identified features that distinguished nondiploid from diploid tumors; the second model identified features that differentiated between ane- 
uploid and tetraploid tumors. R-squared $\left(\mathrm{R}^{2}\right)$ values, or the proportion of variability in the response explained by the model, were used to assess model fit. All predication models were built using a backward selection procedure with the P-value for a feature to leave the model set at .05 .

The extent of HGPIN was transformed to the natural logarithmic scale, after adding 0.1 to all values before transformation, to provide better agreement to the modeling assumptions. The amount of tumor in the block used for FCM was assessed using indicators for amounts of $26-50 \%$, $51-75 \%$, and $\geq 76 \%$, with $\leq 25 \%$ as the reference group. Since the levels of this feature have a natural ordering, we also assessed the amount of tumor in the block using linear and quadratic contrasts. Such contrasts allowed us to determine if DNA ploidy or proliferation increased or decreased as percent tumor increased from one category to the next, and if that rate of increase or decrease remained constant from category to category. Gleason score was evaluated using indicators for scores of 7 and scores of 8 or 9 , treating scores of 6 or less as the reference group. Alternatively, this feature was evaluated with a single indicator for Gleason scores of 8 or 9, with scores of 7 or less as the reference group. We also evaluated predominant Gleason pattern. However, since there were so few patients with predominant Gleason patterns of 2 or 5, we compared patients with predominant Gleason patterns of 4 or 5 to those with predominant Gleason patterns of 3 or less.

\section{RESULTS}

\section{Features at Radical Retropubic Prostatectomy}

The mean (SD) patient age for the 322 cases was 65 years (6.4) with a range of 38 to 78 years. The average (SD) and median overall estimated tumor volume was 7.2 (11.7) cubic centimeters (cc) and 3.0 cc, respectively, with a range of 0.004 cc to 131.25 cc. Two hundred fifty-six $(80 \%)$ of the cancers were pathologically confined and $66(20 \%)$ were extraprostatic. Sixty-nine cases $(21 \%)$ had $\leq 25 \%$ tumor in the tissue block, 121 cases (38\%) had $26-50 \%, 94$ cases $(29 \%)$ had $51-75 \%$, and 38 cases $(12 \%)$ had $\geq 76 \%$. The mean (SD) Gleason score was $6.7(0.8)$ with a range of 5 to 9 . Most cases $(87 \%)$ had Gleason scores of 6 or 7 . Seventy-seven (24\%) cases had a predominant Gleason pattern of 4 or 5 , while the remaining $245(76 \%)$ had predominant Gleason patterns of 3 or less. One hundred eighteen cases (37\%) had histologic evidence of a biopsy needle track. Most of these $(70 \%)$ were fibrohistiocytic reactions. A few (5 or $1.6 \%$ ) contained focal granuloma formation. The average (SD) extent of HGPIN was $4.5 \%(6.7 \%)$, ranging from $0 \%$ to $50 \%$.

\section{DNA Ploidy by Flow Cytometry}

There were 241 diploid (75\%), 67 tetraploid (21\%), and 14 aneuploid (4\%) tumors out of the 322 total cases. The univariate predictors of non-diploid versus diploid tumors are summarized in Table 1. The final joint prediction model is shown in Table 2. The linear contrast for the amount of tumor in the tissue block was jointly significantly associated with DNA ploidy ( $P=.003$ ). After adjusting for the other predictors, moving from one tumor block category to the next (e.g., from $\leq 25 \%$ to $26-50 \%$ tumor) increased the odds of a non-diploid tumor by $25 \%$. The quadratic contrast for this feature was not statistically significant $(P=.77)$, indicating that there was no evidence that the rate of increase in the odds of a non-diploid tumor varied with the amount of tumor in the tissue block. Cases with Gleason scores of 8 or 9 were 2.7 times more likely to be non-diploid, compared to cases with scores of 7 or less $(P=.019)$. Cases with Gleason score 7 were more likely to be non-diploid compared to those with scores of 6 or less. However, this difference did not reach statistical significance $(P=.066)$. After adjusting for the amount of tumor in the block and Gleason score, each one-unit increase in the extent of HGPIN on the natural logarithmic scale increased the odds of a non-diploid tumor by $21 \%$ $(P=.026)$.

We also evaluated the ability of predominant Gleason pattern to distinguish between non-diploid and diploid tumors by FCM. Although predominant Gleason pattern was significantly associated with ploidy by FCM univariately, this feature was not predictive of ploidy after adjusting for the amount of tumor in the block and the extent of HGPIN $(P=.062)$.

The univariate predictors of aneuploid versus tetraploid tumors are found in Table 1 . After adjusting

TABLE 1. Univariate Predictors of DNA Ploidy by FCM

\begin{tabular}{|c|c|c|c|c|}
\hline \multirow{2}{*}{ Predictor } & \multicolumn{2}{|c|}{$\begin{array}{l}\text { Non-Diploid } \\
\text { versus Diploid }\end{array}$} & \multicolumn{2}{|c|}{$\begin{array}{l}\text { Aneuploid } \\
\text { versus } \\
\text { Tetraploid }\end{array}$} \\
\hline & $\begin{array}{l}\text { Odds } \\
\text { Ratio }\end{array}$ & P-Value & $\begin{array}{l}\text { Odds } \\
\text { Ratio }\end{array}$ & P-Value \\
\hline Evidence of needle track & 0.95 & 0.856 & 1.00 & 0.994 \\
\hline Extent of HGPIN ${ }^{a}$ & 1.12 & 0.142 & 0.88 & 0.451 \\
\hline \multicolumn{5}{|l|}{ Amount of tumor in the block } \\
\hline $26-50 \%$ & 1.54 & 0.294 & 0.17 & 0.165 \\
\hline $51-75 \%$ & 2.77 & 0.013 & 0.80 & 0.810 \\
\hline$\geq 76 \%$ & 4.29 & 0.002 & 2.40 & 0.354 \\
\hline \multicolumn{5}{|l|}{ Amount of tumor in the block } \\
\hline Linear contrast & 1.29 & $<0.001$ & 1.23 & 0.183 \\
\hline Quadratic contrast & 1.00 & 0.991 & 1.74 & 0.087 \\
\hline \multicolumn{5}{|l|}{ Gleason score at RRP } \\
\hline 7 & 2.19 & 0.008 & 3.32 & 0.282 \\
\hline 8 or 9 & 4.69 & $<0.001$ & 18.38 & 0.011 \\
\hline Gleason score at RRP of 8 or 9 & 3.00 & 0.004 & 7.38 & 0.002 \\
\hline
\end{tabular}

${ }^{a}$ Predictor was transformed to the natural logarithmic scale.

FCM, flow cytometry; HGPIN, high grade prostatic intraepithelial neoplasia; RRP, radical retropubic prostatectomy. 
TABLE 2. Jointly Significant Predictors of Non-Diploid versus Diploid Tumors by FCM

\begin{tabular}{lcc}
\hline \multicolumn{1}{c}{ Predictor } & Odds Ratio (95\% C.I.) & P-Value \\
\hline Amount of tumor in the block & & \\
$\quad$ Linear contrast & $1.25(1.08,1.45)$ & 0.003 \\
Gleason score at RRP 8 or 9 & $2.69(1.18,6.15)$ & 0.019 \\
Extent of HGPIN $^{a}$ & $1.21(1.02,1.44)$ & 0.026 \\
\hline \multicolumn{2}{c}{${ }^{a}$ Predictor was transformed to the natural logarithmic scale. } \\
FCM, flow cytometry; RRP, radical retropubic prostatectomy; HGPIN, \\
high grade prostatic intraepithelial neoplasia.
\end{tabular}

for Gleason score $(P=.002)$, no other feature was a significant predictor of ploidy in this subset of cases with non-diploid tumors, although amount of tumor in the block approached statistical significance $(P=.087)$. Cases with Gleason scores of 8 or 9 were 7.4 times as likely to be aneuploid than tetraploid compared to cases with scores of 7 or less. Similarly, cases with a predominant Gleason pattern of 4 or 5 were more likely to be aneuploid than tetraploid compared to cases with predominant Gleason patterns of 3 or less $(P=.020)$.

The percent of cases with a needle track was essentially constant across the three ploidy classifications: $37 \%$ of the diploid cases, $36 \%$ of the tetraploid cases, and $36 \%$ of the aneuploid cases. Therefore, the presence of a needle track was not significantly associated with DNA ploidy. Furthermore, of the five specimens with focal granuloma formation, all were DNA diploid.

\section{Percent S Phase by Flow Cytometry}

The mean (SD) \%S was $3.1 \%(2.8 \%)$, ranging from $0 \%$ to $25 \%$, with a median of $2 \%$. There was strong evidence that \%S was not normally distributed. Transformation to the natural logarithmic scale, after adding $0.1 \%$ to all $\% \mathrm{~S}$ values before transformation because three cases had measurements of $0 \%$, provided better agreement to the linear regression assumptions.

Univariate predictors of $\% \mathrm{~S}$ are summarized in Table 3. After adjusting for Gleason score at RRP, no other features were significantly associated with $\%$ S. Cases with Gleason scores of 8 or 9 had increased proliferation, compared to cases with scores 7 or less $(P=.002)$. Cases with Gleason scores of 8 or 9 had a mean \%S value of $4.8 \%$. Cases with Gleason scores of 6 or less had a mean \%S value of $2.6 \%$ while those with Gleason scores of 7 had a mean \%S of $3.2 \%$. Predominant Gleason pattern was also significantly associated with \%S $(P<$ .001). Cases with a predominant Gleason pattern of 4 or 5 had a mean $\% S$ value of $4.0 \%$, while patients with a predominant Gleason pattern of 3 or less had a mean $\%$ S value of $2.8 \%$.

\section{Percent S Phase + Percent G2M by Flow Cytometry}

The mean (SD) \%S + \%G2M was $10.5 \%$ (8.6\%), ranging from $2 \%$ to $81 \%$, with a median of $8 \%$. Note that the 14 aneuploid tumors did not have $\% \mathrm{~S}+$ \%G2M measurements. \%S + \%G2M was analyzed on the natural logarithmic scale since there was evidence that the distribution of this feature was not normal.

Univariate predictors of $\% \mathrm{~S}+\% \mathrm{G} 2 \mathrm{M}$ are summarized in Table 3 . The final prediction model for $\% \mathrm{~S}+\% \mathrm{G} 2 \mathrm{M}$ is found in Table 4 . In univariate and multivariate analyses, both the amount of tumor in the block and Gleason score were significantly associated with \%S + \%G2M. Holding Gleason score constant, each increase from one tumor block category to the next increased $\% \mathrm{~S}+\% \mathrm{G} 2 \mathrm{M}$ by $4 \%(P=$ .024). The quadratic contrast for this feature was not statistically significant $(P=.84)$. This indicates there was no evidence that the rate of increase in $\% \mathrm{~S}+\% \mathrm{G} 2 \mathrm{M}$ varied with the amount of tumor in the tissue block used for FCM. Cases with scores of 7 or scores of 8 or 9 had higher levels of proliferation compared to cases with scores of 5 or $6(P=$ .003 and $P=.034$, respectively), after adjusting for the amount of tumor in the tissue block.

We also evaluated the association between $\% \mathrm{~S}+$ $\%$ G2M by FCM and predominant Gleason pattern (4 or 5 versus 3 or less). The results were similar to the analysis of Gleason score. Predominant Gleason pattern was significantly associated with \%S + $\% \mathrm{G} 2 \mathrm{M}$, even after adjusting for the amount of tumor in the block $(P=.011)$.

\section{DISCUSSION}

In this study, we evaluated H\&E histologic features of 322 RRP formalin-fixed, paraffin-embedded tissue blocks used for determining DNA ploidy, \%S and $\% \mathrm{~S}+\% \mathrm{G} 2 \mathrm{M}$ by FCM. We found that the

TABLE 3. Univariate Predictors of Proliferation by FCM

\begin{tabular}{|c|c|c|c|c|}
\hline \multirow{2}{*}{ Predictor } & \multicolumn{2}{|c|}{$\% \mathrm{~S}$} & \multicolumn{2}{|c|}{$\% \mathrm{~S}+\% \mathrm{G} 2 \mathrm{M}$} \\
\hline & $\mathrm{R}^{2}(\%)$ & P-Value & $\mathrm{R}^{2}(\%)$ & P-Value \\
\hline Evidence of needle track & 0.2 & 0.421 & 0.2 & 0.484 \\
\hline Extent of HGPIN ${ }^{a}$ & 0.0 & 0.714 & 0.5 & 0.221 \\
\hline \multicolumn{5}{|l|}{ Amount of tumor in the block } \\
\hline $26-50 \%$ & 2.4 & 0.269 & 4.6 & 0.092 \\
\hline $51-75 \%$ & & 0.226 & & 0.014 \\
\hline$\geq 76 \%$ & & 0.146 & & $<0.001$ \\
\hline \multicolumn{5}{|l|}{ Amount of tumor in the block } \\
\hline Linear contrast & 2.2 & 0.220 & 4.4 & $<0.001$ \\
\hline Quadratic contrast & & 0.010 & & 0.733 \\
\hline \multicolumn{5}{|l|}{ Gleason score at RRP } \\
\hline 7 & 3.7 & 0.156 & 6.0 & $<0.001$ \\
\hline 8 or 9 & & $<0.001$ & & 0.004 \\
\hline Gleason score at RRP of 8 or 9 & 3.1 & 0.002 & 1.1 & 0.072 \\
\hline
\end{tabular}

$a$ Predictor was transformed to the natural logarithmic scale.

FCM, flow cytometry; HGPIN, high grade prostatic intraepithelial neoplasia; RRP, radical retropubic prostatectomy. 
TABLE 4. Jointly Significant Predictors $\% S+\% G 2 M$ by FCM

\begin{tabular}{lc}
\hline \multicolumn{1}{c}{ Predictor } & P-Value \\
\hline \multicolumn{2}{c}{ Amount of tumor in the block } \\
$\quad$ Linear contrast & 0.024 \\
Gleason score at RRP & 0.003 \\
7 & 0.034 \\
8 or 9 & \\
\hline
\end{tabular}

FCM, flow cytometry; RRP, radical retropubic prostatectomy.

amount of tumor in the tissue block, Gleason score of the cancer, and the extent of HGPIN were significantly associated with DNA ploidy in a multivariate model. The amount of tumor in the block and Gleason score were significantly associated with $\% \mathrm{~S}+$ \%G2M. The presence of a needle track was not associated with ploidy or proliferation by FCM.

Standard prognostic markers in prostate cancer include serum PSA (13-17), Gleason score (2, 18$24)$, and pathologic stage (25-28). DNA ploidy is generally accepted by many as an independent prognostic marker, particularly if the cancer is extraprostatic at the time of RRP $(1-3,5,9,29)$. At Mayo Clinic, for example, our urologists request DNA ploidy determination of all patients undergoing RRP. However, most of the data are derived from flow cytometric analysis of paraffinembedded tissue sections, and FCM cannot distinguish among benign epithelium, stromal and inflammatory cells, HGPIN, and cancer cells. DNA non-diploid rates using methodologies that quantitate cells by direct visualization are higher than those from FCM $(30,31)$. This raises the possibility that the ploidy results by FCM may be influenced by factors other than the DNA content of the tumor cells in the tissue block (31).

In our analysis, the amount of tumor in the tissue block, expressed as a percentage of the total surface area, was predictive of the ploidy result by FCM. Admittedly, the percent of non-diploid cases was somewhat low ( $25 \%$ with only $4 \%$ aneuploid). However, this is clearly contingent upon the amount of cancer in the paraffin tissue block used for FCM. Specifically, the more tumor present in the block, the greater the likelihood of a non-diploid result. In pairwise univariate analyses comparing the ability of the amount of tumor in the block to distinguish diploid from non-diploid tumors, the only comparisons that were not statistically significant were $\leq 25 \%$ versus $26-50 \%(P=.29)$ and $51-75 \%$ versus $\geq 76 \%(P=.27)$. These data suggest that there are significant differences in the non-diploid rates between tumors that constitute less than $50 \%$ versus greater than $50 \%$ of the tissue block.

The studies that fail to recognize ploidy as an independent marker of prostate cancer highlight the strong association between Gleason score and DNA ploidy $(9,15,32)$. In our study, tumors that had Gleason scores of 8 or 9 had a greater than two-fold increased likelihood of being either DNA aneuploid or tetraploid by FCM compared to tumors with Gleason scores of 7 or less. Consequently, this study was designed to assess the impact of the amount of tumor in the block on FCM results after adjusting for Gleason score. Even after adjusting for Gleason score, tumor burden in the tissue block was still significantly associated with DNA ploidy by FCM.

HGPIN in tissue sections has cytologic features identical to cancer. In our series of cases, the smaller the tumor volume in the block used for FCM, the greater the amount of HGPIN. Tumor volumes at RRP are shrinking (33-35). The specimens analyzed in this study represent a subset of 454 cases in which $22 \%$ had tumor volumes less than $0.5 \mathrm{cc}$. Furthermore, of the 322 specimens evaluated for DNA ploidy by FCM, $21 \%$ had tumor volumes less than $25 \%$ of the overall tissue surface area in the paraffin block. Consequently, we wanted to investigate whether the extent of HGPIN in tissue sections was associated with higher non-diploid rates by FCM. In our institution, those RRP specimens in which tumor volume represents less than $10 \%$ of the overall surface area are processed for digital image analysis (DIA) in order to assess for cancer ploidy (36). Therefore, it is possible that the impact of tumor volume in this study has been underestimated since, in general, those specimens with very small cancer foci are usually processed for DIA. Despite that, the extent of HGPIN in our study was still significantly associated with DNA ploidy in multivariate analyses, even after adjusting for the amount of tumor in the block and Gleason score.

Similarly, we wanted to address whether reactive and inflammatory changes in the RRP specimen were associated with DNA ploidy by FCM. One consistent marker of inflammatory changes is the presence of a needle track status-post biopsy. In our study, $37 \%$ of the blocks used for FCM had histologic evidence of a needle track. This was typically recognized as either a fibrin clot or a fibrohistiocytic reaction. Five cases $(1.6 \%)$ had focal granuloma formation. However, the presence of a needle track was not significantly associated with DNA ploidy in either a univariate or multivariate setting.

When repeating these analyses in the subset of non-diploid tumors, only Gleason score significantly distinguished between aneuploid and tetraploid tumors. Again, this highlights the strong association between Gleason score and DNA ploidy by FCM in prostate cancer. However, there were only 14 aneuploid tumors in our study of 322 RRP specimens evaluated for DNA ploidy by FCM. Therefore, our statistical power to detect a significant association between the amount of tumor in 
the block and DNA ploidy in the subset of tetraploid and aneuploid cases was limited.

Proliferation as a prognostic marker in prostate cancer, although less well defined, has also been shown to be a marker for outcome $(22,37-39)$. We wanted to investigate what, if any, impact the above-noted histologic features had on the proliferation indices (\%S and $\% \mathrm{~S}+\% \mathrm{G} 2 \mathrm{M})$ quantified by FCM. For $\% \mathrm{~S}$ alone, the only parameter predictive of $\% \mathrm{~S}$ was Gleason score. The average $\% \mathrm{~S}$ value was almost twice as high ( $4.8 \%$ versus $2.6 \%)$ for tumors with Gleason scores of 8 or 9 as compared to tumors with Gleason scores of 6 or less.

Conversely, if one includes the percent G2M fraction in the proliferation index, both Gleason score and amount of cancer in the tissue block were associated with proliferation. Averaging over Gleason score, the average $\% \mathrm{~S}+\% \mathrm{G} 2 \mathrm{M}$ value ranged from a low of $8.2 \%$ using tissue blocks with $\leq 25 \%$ cancer to $16.4 \%$ using blocks with $\geq 76 \%$ cancer. This represents a doubling of the proliferation index.

We also assessed the association of predominant Gleason pattern with ploidy and proliferation. This alteration to the routine Gleason scoring process has recently been touted as a superior way of assessing prostate cancer biologic potential (40). In our study, we found similar results when we replaced Gleason score with predominant Gleason pattern. Specifically, incorporating predominant Gleason pattern into the model showed that predominant Gleason pattern, amount of tumor in the block, and extent of HGPIN were all significantly associated with ploidy. Similar univariate and multivariate associations were seen with predominant Gleason pattern in predicting proliferation levels.

In summary, DNA ploidy by FCM was significantly associated with the amount of cancer in the paraffin tissue block, Gleason score, and the extent of HGPIN. Proliferation by FCM was significantly associated with the amount of tumor in the block and Gleason score. Non-diploid rates, after accounting for Gleason score and the extent of HGPIN, were highest when the amount of tumor in the block exceeded $50 \%$ of benign tissue. Percent $S+$ $\%$ G2M proliferation measurements doubled as the amount of tumor increased from $\leq 25 \%$ to $\geq 76 \%$. Only Gleason score was significantly associated with the more commonly used index of proliferation, \%S. Furthermore, the presence of a needle track was not associated with DNA ploidy and proliferation by FCM. While our results may not be applicable to all scenarios of prostate cancer prognostication, our study emphasizes the strong association between Gleason score and ploidy and highlights the requirement of selecting a paraffin block containing an appropriate amount of tumor for flow cytometric analysis. Furthermore, with tumor volumes at RRP shrinking, it is important to recognize the effect that the extent of HGPIN and cancer in the tissue block have on ploidy assessments by FCM.

Acknowledgments: The authors thank the technical staff of the Image Morphometry and Flow Cytometry Laboratories at Mayo Clinic for their hard work.

\section{REFERENCES}

1. Winkler HZ, Rainwater LM, Myers RP, Farrow GM, Therneau $\mathrm{TM}$, Zincke $\mathrm{H}$, et al. Stage D1 prostatic adenocarcinoma: significance of nuclear DNA ploidy patterns studied by flow cytometry. Mayo Clin Proc 1988;63:103-12.

2. Dejter SW, Jr, Cunningham RE, Noguchi PD, Jones RV, Moul JW, McLeod DG, et al. Prognostic significance of DNA ploidy in carcinoma of prostate. Urology 1989;33:361-6.

3. Nativ O, Winkler HZ, Raz Y, Therneau TM, Farrow GM, Myers RP, et al. Stage C prostatic adenocarcinoma: flow cytometric nuclear DNA ploidy analysis. Mayo Clin Proc 1989;64:911-9.

4. Montgomery BT, Nativ O, Blute ML, Farrow GM, Myers RP, Zincke $\mathrm{H}$, et al. Stage B prostate adenocarcinoma. Flow cytometric nuclear DNA ploidy analysis. Arch Surg 1990;125: 327-31.

5. Lieber MM. Prognostic importance of nuclear DNA content measured by flow cytometry for patients with adenocarcinoma of the prostate. Urol Int 1991;47:74-6.

6. Deitch AD, deVere White RW. Flow cytometry as a predictive modality in prostate cancer. Hum Pathol 1992;23:352-9.

7. Bratt O, Anderson H, Bak-Jensen E, Baldetorp B, Lundgren R. Metaphase cytogenetics and DNA flow cytometry with analysis of S-phase fraction in prostate cancer: influence on prognosis. Urology 1996;47:218-24.

8. Astrom L, Weimarck A, Aldenborg F, Delle U, Hanson C, Verbiene I, et al. S-phase fraction related to prognosis in localised prostate cancer. No specific significance of chromosome 7 gain or deletion of 7q31.1. Int J Cancer 1998;79: 553-9.

9. Ritchie AW, Dorey F, Layfield LJ, Hannah J, Lovrekovich H, deKernion JB. Relationship of DNA content to conventional prognostic factors in clinically localised carcinoma of the prostate. Br J Urol 1988;62:245-60.

10. Hussain MH, Powell I, Zaki N, Maciorowski Z, Sakr W, KuKuruga $\mathrm{M}$, et al. Flow cytometric DNA analysis of fresh prostatic resections. Correlation with conventional prognostic parameters in patients with prostate cancer. Cancer 1993;72: 3012-9.

11. Nichols T, Speights VO, Measel J. Analysis of prostate cancer by flow cytometry and correlation with Gleason scores. Ann NY Acad Sci 1993;677:431-2.

12. Zanetta G, Keeney GL, Cha SS, Farr GH, Jr, Katzmann JA, Wieand HS, et al. Flow-cytometric analysis of deoxyribonucleic acid content in advanced ovarian carcinoma: its importance in long-term survival. Am J Obstet Gynecol 1996; 175:1217-25.

13. Badalament RA, O'Toole RV, Young DC, Drago JR. DNA ploidy and prostate-specific antigen as prognostic factors in clinically resectable prostate cancer. Cancer 1991;67:301423.

14. Andersson L. Prognostic indicators in prostatic cancer. Nippon Hinyokika Gakkai Zasshi 1992;83:794-7.

15. Chisholm GD, Hedlund PO, Adolfsson J, Denis LJ, Friberg S, Johansson JE, et al. The TNM system of 1992. Comments from the TNM working group. Consensus Conference on Diagnosis and Prognostic Parameters in Localized Prostate 
Cancer. Stockholm, Sweden, May 12-13, 1993. Scand J Urol Nephrol Suppl 1994;162:107-27.

16. Gao X, Porter AT, Grignon DJ, Pontes JE, Honn KV. Diagnostic and prognostic markers for human prostate cancer. Prostate 1997;31:264-81.

17. Diaz JI, Mora LB, Austin PF, Muro-Cacho CA, Cantor AB, Nicosia SV, et al. Predictability of PSA failure in prostate cancer by computerized cytometric assessment of tumoral cell proliferation. Urology 1999;53:931-8.

18. Murphy GP, Busch C, Abrahamsson PA, Epstein JI, McNeal JE, Miller GJ, et al. Histopathology of localized prostate cancer. Consensus Conference on Diagnosis and Prognostic Parameters in Localized Prostate Cancer. Stockholm, Sweden, May 12-13, 1993. Scand J Urol Nephrol Suppl 1994;162: 7-42,115-27.

19. Vesalainen S, Nordling S, Lipponen P, Talja M, Syrjanen K. Progression and survival in prostatic adenocarcinoma: a comparison of clinical stage, Gleason grade, S-phase fraction and DNA ploidy. Br J Cancer 1994;70:309-14.

20. Anderson PR, Hanlon AL, Patchefsky A, Al-Saleem T, Hanks GE. Perineural invasion and Gleason 7-10 tumors predict increased failure in prostate cancer patients with pretreatment PSA less than $10 \mathrm{ng} / \mathrm{ml}$ treated with conformal external beam radiation therapy. Int J Radiat Oncol Biol Phys 1998; 41:1087-92.

21. Fujikawa K, Sasaki M, Itoh T, Arai Y, Ogawa O, Yoshida O. Combining volume-weighted mean nuclear volume with Gleason score and clinical stage to predict more reliably disease outcome of patients with prostate cancer. Prostate 1998;37:63-9.

22. Mora LB, Moscinski LC, Diaz JI, Blair P, Cantor AB, PowSang JM. Stage B Prostate Cancer. Correlation of DNA Ploidy Analysis With Histological and Clinical Parameters. Cancer Control 1999;6:587-91.

23. Tefilli MV, Gheiler EL, Tiguert R, Sakr W, Grignon DJ, Banerjee M, et al. Should Gleason score 7 prostate cancer be considered a unique grade category? Urology 1999;53:372-7.

24. Vassilikos EJ, Yu H, Trachtenberg J, Nam RK, Narod SA, Bromberg IL, et al. Relapse and cure rates of prostate cancer patients after radical prostatectomy and 5 years of follow-up. Clin Biochem 2000;33:115-23.

25. Grayhack JT, Assimos DG. Prognostic significance of tumor grade and stage in the patient with carcinoma of the prostate. Prostate 1983;4:13-31.

26. Coetzee LJ, Layfield LJ, Hars V, Paulson DF. Proliferative index determination in prostatic carcinoma tissue: is there any additional prognostic value greater than that of Gleason score, ploidy and pathological stage? [see comments]. J Urol 1997;157:214-8.

27. Ramos CG, Carvalhal GF, Smith DS, Mager DE, Catalona WJ. Clinical and pathological characteristics, and recurrence rates of stage T1c versus T2a or T2b prostate cancer. J Urol 1999;161:1525-9.

28. D'Amico AV, Whittington R, Malkowicz SB, Wu YH, Chen M, Art M, et al. Combination of the preoperative PSA level, biopsy gleason score, percentage of positive biopsies, and MRI T-stage to predict early PSA failure in men with clinically localized prostate cancer. Urology 2000;55:572-7.

29. Lieber MM, Cheng WS. The role of nuclear DNA ploidy in the prognosis and management of patients with prostate cancer. Compr Ther 1991;17:26-32.

30. Pindur A, Chakraborty S, Welch DG, Wheeler TM. DNA ploidy measurements in prostate cancer: differences between image analysis and flow cytometry and clinical implications. Prostate 1994;25:189-98.

31. Bowman R, Kanacki ZA, Garberoglio C, Chase DR. Comparison between image and flow cytometry. A priori factors that influence technique. Anal Quant Cytol Histol 1995;17:27683.

32. Adolfsson J. Prognostic value of deoxyribonucleic acid content in prostate cancer: a review of current results. Int J Cancer 1994;58:211-6.

33. Catalona WJ, Smith DS, Ratliff TL, Basler JW. Detection of organ-confined prostate cancer is increased through prostate-specific antigen-based screening [see comments]. JAMA 1993;270:948-54.

34. Farkas A, Schneider D, Perrotti M, Cummings KB, Ward WS. National trends in the epidemiology of prostate cancer, 1973 to 1994: evidence for the effectiveness of prostate-specific antigen screening. Urology 1998;52:444-9.

35. Roberts RO, Bergstralh EJ, Katusic SK, Lieber MM, Jacobsen SJ. Decline in prostate cancer mortality from 1980 to 1997 , and an update on incidence trends in Olmsted County, Minnesota. J Urol 1999;161:529-33.

36. Sebo TJ. Digital image analysis. Mayo Clin Proc 1995;70: 81-2.

37. McLoughlin J, Foster CS, Price P, Williams G, Abel PD. Evaluation of Ki-67 monoclonal antibody as prognostic indicator for prostatic carcinoma. Br J Urol 1993;72:92-7.

38. Ahlgren G, Lindholm K, Falkmer U, Abrahamsson PA. A DNA cytometric proliferation index improves the value of the DNA ploidy pattern as a prognosticating tool in patients with carcinoma of the prostate. Urology 1997;50:379-84.

39. Hui AM, Li X, Shi YZ, Torzilli G, Takayama T, Makuuchi M. p27(Kip1) expression in normal epithelia, precancerous lesions, and carcinomas of the gallbladder: association with cancer progression and prognosis. Hepatology 2000;31:1068-72.

40. Stamey TA, McNeal JE, Yemoto CM, Sigal BM, Johnstone IM. Biological determinants of cancer progression in men with prostate cancer. JAMA 1999;281:1395-400. 